\title{
Editorials
}

\section{Integration of care:}

\author{
a bridge too far?
}

With rising numbers of people with complex and long-term conditions, integrated health and social care is being hailed as one of the keys to combining better patient care with increased cost effectiveness in the face of budgetary pressures. What is integration, can it live up to this hope, and what might it mean for general practice?

\section{DEFINITION OF INTEGRATED CARE}

The principles underlying the integration of care may be summarised as patientcentred, primary care led care, with multiprofessional teams where each profession retains their professional autonomy but works across professional boundaries, ideally with a shared electronic GP record'.' The evidence suggests that successful integration of care requires sustained and effective leadership. ${ }^{2}$ The role of GPs, with their breadth of knowledge and their experience of working with a wide range of disciplines, will be vital if such a vision is to be realised.

\section{GENERAL PRACTICE: LEADING THE WAY?}

For patients with complex multimorbidity and long-term conditions, a care planning model, through which patients, health professionals, and carers work collaboratively to set person-centred goals, plan care, and review outcomes on a regular basis has been shown to be effective. $^{3}$ However, without the right infrastructure and investment, general practice will not be able to be an effective provider and facilitator of such models of integrated care. Rising levels of demand, for example, make it difficult for GPs to provide the longer consultation times needed to deliver better, more integrated care to patients with complex multimorbidity and social care needs. ${ }^{4}$ In addition, the lack of efficient, effective, and compatible systems and protocols for the sharing of patient information inhibits coordination with other services and continuity of care. GP federations, associations of practices, and community primary care teams, are one model through which general practice can act as a hub for the provision of a broader range of more integrated services outside the hospital setting. This has been a driver of integrated

\section{without the right infrastructure and investment,} general practice will not be able to be an effective provider and facilitator of such models of integrated care.

care in a number of locations, such as Redbridge, London, and Cumbria. ${ }^{5}$

\section{SERVICE REDESIGN}

The redesign of services also has the potential to deliver better integration by placing a greater focus on early identification and prevention, preventing unnecessary hospital admission, and providing more community-based support. Key to this is the development of new ways of working between generalists and specialists as part of multiprofessional teams, using, for example the 'Teams without Walls' principles. ${ }^{6}$ The central challenge is to ensure that services are designed around the needs of the whole person, transcending the boundaries between multiple conditions and between health and social care. This will be a key task for the new clinical commissioning groups (CCGs) in England but it is not yet clear to what degree they will have the autonomy, power, and capabilities needed to drive the system-wide change that is required. One critical factor will be the way in which the NHS Commissioning Board carries out its role, for instance in developing the Commissioning Outcomes Framework, and in shaping the work of clinical senates and networks.

\section{EVALUATING OUTCOMES}

Integrated care is commonly cited as being associated with a number of benefits, including better health outcomes, improved patient experience, more cost-effective care, reduced health inequalities, and enhanced job satisfaction. ${ }^{7}$ In practice, the benefits may not always be so clear cut. A recent evaluation of the Department of Health's integrated care pilots ${ }^{8}$ found that although they did lead to better processes, such as an increase in the use of care plans and improved organisation of care following hospital discharge, the patients themselves did not generally feel that this had translated into an overall improvement in their experience of care. On some measures, such as continuity of care, patient experiences had actually declined. In addition, although there were significant reductions in elective admissions and outpatient attendances, these were balanced by increases in the cost of emergency admissions.

\section{INTEGRATION, COMPETITION, AND CHOICE}

The Health and Social Care Bill raised concerns about a market-based model of NHS provision in England acting as a barrier to integration. In response, the draft legislation was amended to ensure that, despite the introduction of policies such as any qualified provider, services could be integrated around the needs of patients and carers. Monitor, as the independent economic regulator, will be obliged to enable integration where this is in the best interests of patients, and can set and enforce license conditions in pursuance of this aim. CCGs and the NHS Commissioning Board will also be required
"Key challenges include overcoming cultural and professional boundaries, and reconciling the disparate goals and incentives created by different eligibility rules and funding arrangements. 
to promote integration as well as enabling patient choice.

Nonetheless, there remains an urgent need to clarify how competition, choice, and integration will work together and how integration will fit with the principles and rules for cooperation and competition, and with competition law. ${ }^{9}$ The government's intention is to do so through the proposed 'choice mandate'. This is intended to establish the parameters for the operation of choice and competition in the NHS, and will inform the development of guidance by the NHS Commissioning Board on, for example, which services can be 'bundled' and integrated. One possible means of 'squaring this circle' between integration and choice is the concept of competition between integrated organisations. However, in these difficult financial times, this concept has been criticised as almost ludicrously impractical, requiring huge capital investment to create the capacity for such competition'. ${ }^{10}$

\section{MIND THE GAP: HEALTH AND SOCIAL \\ CARE}

Another significant barrier to integration is the separation of health and social care. Key challenges include overcoming cultural and professional boundaries, and reconciling the disparate goals and incentives created by different eligibility rules and funding arrangements. The Scottish Executive has recently set out plans for the formation of Health and Social Care Partnerships, to tackle 'cost shunting' between health and local government and shift the balance of resources away from institutional care. In England, some of the best outcomes have been achieved by Torbay Care Trust through the use of pooled budgets across health and social care, leading to impressive reductions in levels of hospital admissions. However, concerns have been expressed that such results could be more difficult to achieve in future as a result of the Health and Social Care Act, which removes care trusts' ability to combine service provision with the commissioning of health and social care. ${ }^{11}$

\section{INTEGRATED CARE: A BRIDGE TOO FAR?}

The evidence shows that realising the benefits of integrated care is by no means straightforward, especially against a backdrop of increased competition. To succeed, integration must build on the ability of general practice to act as a hub for truly patient-centred care, working across professional and service boundaries. The goal must be to equip and empower GPs to take the lead in playing a proactive role in the management of those with long-term conditions and multimorbidities, and in reaching out to high-risk groups. Without this, integration could all too easily prove to be a bridge too far for patients, GPs, and the NHS.

\section{Nigel Mathers,}

Vice-Chair of RCGP Council, London, and Professor of Primary Medical Care and Head of Academic Unit of Primary Medical Care, The University of Sheffield, Sheffield.

\section{Mark Thomas}

Head of Policy \& Public Affairs, Policy and Communications, Royal College of General Practitioners, London.

\section{Competing interests}

The authors have declared no competing interests.

DOI: 10.3399/bjgp12X653462

\section{ADDRESS FOR CORRESPONDENCE}

\section{Nigel Mathers}

Royal College of General Practitioners, 1 Bow Churchyard, London, EC4M 9DQ, UK.

E-mail: nmathersArcgp.org.uk

\section{REFERENCES}

1. Royal College of General Practitioners. Integration of care. London: RCGP, 2012

2. Rosen R, Mountford J, Lewis G, et al. Integration in action: four international case studies. London: The Nuffield Trust, 2011.

3. Royal College of General Practitioners. Care planning: improving the lives of people with long-term conditions. London: RCGP, 2011.

4. Mercer SW, Fitzpatrick B, Gourlay G, et al. More time for complex consultations in a high deprivation practice is associated with increased patient enablement. Br J Gen Pract 2007; 57(545): 960-966.

5. Ham C, Smith J. Removing the policy barriers to integrated care in England. London: The Nuffield Trust, 2010

6. Royal College of Physicians, Royal College of General Practitioners, Royal College of Paediatrics and Child Health. Teams without walls: the value of medical innovation and leadership. London: RCP, 2008.

7. Curry N, Ham C. Clinical and service integration: the route to improved outcomes. London: The King's Fund, 2010.

8. Ernst \& Young, RAND Europe. National evaluation of the Department of Health's integrated care pilots. London: Department of Health, 2012.

9. NHS Future Forum. Integration. London: Department of Health, 2012.

10. Paton C. Competition and integration: the NHS Future Forum's confused consensus. $\mathrm{Br} J$ Gen Pract 2012; 62(596): 116-117.

11. House of Commons Health Committee. Social care: fourteenth report of session 2010-12, Vol 1. London: The Stationery Office Ltd, 2012. 